\title{
Article \\ Optimization of Milling Parameters of Unmodified Calotropis Procera Fiber-Reinforced PLA Composite (UCPFRPC)
}

\author{
Hassan K. Langat ${ }^{1}\left(\mathbb{D}\right.$, Fredrick M. Mwema ${ }^{1,2, *}$, James N. Keraita ${ }^{1}$, Esther T. Akinlabi ${ }^{2,3} \mathbb{D}$, Job M. Wambua ${ }^{1} \mathbb{D}$ \\ and Tien-Chien Jen ${ }^{2}$ (D) \\ 1 Department of Mechanical Engineering, Dedan Kimathi University of Technology, Nyeri 10143, Kenya; \\ hassan.langat@dkut.ac.ke (H.K.L.); james.keraita@dkut.ac.ke (J.N.K.); mavekejob@gmail.com (J.M.W.) \\ 2 Department of Mechanical Engineering Science, University of Johannesburg, Auckland Park, \\ Johannesburg 524, 2006, South Africa; etakinlabi@gmail.com (E.T.A.); tjen@uj.ac.za (T.-C.J.) \\ 3 Pan African University for Life and Earth Sciences Institute, Ibadan 200284, Nigeria \\ * Correspondence: Fredrick.mwema@dkut.ac.ke
}

check for updates

Citation: Langat, H.K.; Mwema, F.M.; Keraita, J.N.; Akinlabi, E.T.; Wambua, J.M.; Jen, T.-C. Optimization of Milling Parameters of Unmodified Calotropis Procera Fiber-Reinforced PLA Composite (UCPFRPC). J. Compos. Sci. 2021, 5, 261. https:// doi.org/10.3390/jcs5100261

Academic Editor: Swadesh Kumar Singh

Received: 5 August 2021

Accepted: 30 August 2021

Published: 1 October 2021

Publisher's Note: MDPI stays neutral with regard to jurisdictional claims in published maps and institutional affiliations.

Copyright: (c) 2021 by the authors. Licensee MDPI, Basel, Switzerland. This article is an open access article distributed under the terms and conditions of the Creative Commons Attribution (CC BY) license (https:/ / creativecommons.org/licenses/by/ $4.0 /)$.

\begin{abstract}
This study involves the optimization of the milling parameters of unmodified Calotropis Procera fiber-reinforced PLA composite (UCPFRPC). The material is prepared from the combination of $20 \%$ Calotropis-Procera and $80 \%$ of PLA by weight. The experiments are designed using the Taguchi methodology, where 16 experiments are obtained using the spindle rotational speed, depth of cut, and feed rate as the parameters. These experiments were conducted while obtaining thermal images using an infrared camera and recording the machining time. The change in mass was then determined and the material removal rate computed. The machined workpieces were then investigated for surface roughness. The study shows that the optimal milling parameters in the machining of UCPFRPC for the lowest surface roughness are $400 \mathrm{rpm}, 400 \mathrm{~mm} / \mathrm{min}$, and $0.2 \mathrm{~mm}$, for the rotational spindle speed, feed rate, and depth of cut. The parameters were $400 \mathrm{rpm}, 100 \mathrm{~mm} / \mathrm{min}$, and $1.2 \mathrm{~mm}$ for the largest MRR, and $400 \mathrm{rpm}, 400 \mathrm{~mm} / \mathrm{min}$, and $0.2 \mathrm{~mm}$ for the least average milling temperature. In all the responses, the depth of cut is the most significant factor.
\end{abstract}

Keywords: average milling temperature; Calotropis Procera; depth of cut; feed rate; material removal rate; spindle rotational speed; surface roughness

\section{Introduction}

Natural fiber reinforced composites are extensively finding applications in various fields such as automotive and construction as a replacement to synthetic fiber reinforced composites [1]. The binding component-matrix can either be synthetic polymer or bio polymer. Natural fiber-reinforced synthetic polymers have been studied by a number of researchers due to their attractive mechanical properties. For instance, Yousif et.al. studied the flexural properties of treated and untreated kenaf reinforced epoxy composites [2]. Vaneewari et.al. studied the effect of silane coupling agent on the mechanical strength of sugarcane bagasse and polypropylene [3].

Most recently, studies have focused on fully degradable composites based on natural fiber and bio-polymer matrix $[4,5]$. This has been motivated by the properties arising from the components, such as sustainability, abundance, low density, and low cost of these materials [6]. For polymer composites to be fully utilized during applications, there is need for post-manufacturing optimization, such as machining prior to mechanical assembly to other components [7]. However, machining of composites has been limited by machining induced damages [8]. These damages include delamination and melting during machining, which has been proven to have long term effects on dimensional stability due to residual stresses leading to fatigue failure [7].

Several efforts are ongoing in trying to overcome these challenges for polymer composites. As such, several studies have been undertaken. For instance, Roy et.al. studied 
machinability of natural fiber reinforced polymer composite: conventional vs. ultrasonically assisted machining [9]. Jamal et.al. studied the effect of machining parameters on delamination during milling of banana fiber reinforced polyester composite [10]. Zhang et.al. studied the effects of cutting force in machining of fiber-reinforced polymer matrix [11]. Wang et. al. studied the impacts of machining temperature in milling of carbon fiber-reinforced polymer composites [12]. Nagamadhu et al. studied the impact parameters during drilling of natural fiber reinforced chaired epoxy composites [13]. Vijaykumar et.al. the machining characteristics of hemp fiber-reinforced composites [14].

Although much is available in literature, machining quality depends on the specific polymer-composite. Therefore, there is a need to undertake more studies in a wider range of polymer composite types. In this article, milling parameters, i.e., spindle rotational speed, depth of cut, and feed rate are optimized using the Taguchi methodology. Unmodified Calotropis Procera fiber-reinforced PLA composite (UCPFRPC) is studied. Specifically, Material removal rate, surface roughness, and milling temperatures are studied. The results of this article form a wider contribution to science, towards the provision of information necessary to steer ahead the applicability of bio-composites.

\section{Materials and Methods}

\subsection{Design of Experiments}

Four levels of each machining parameter were chosen from trial experiments conducted on the unmodified Calotropis Procera fiber-reinforced PLA composite, as presented in Table 1. The experiments were then designed using the Taguchi Method. As a result, sixteen experimental combinations were produced from the parameter levels. The L16 orthogonal array was chosen in the design of experiment, as shown in Table 2.

Table 1. Milling parameters and levels.

\begin{tabular}{ccccccc}
\hline Parameters & & & \multicolumn{4}{c}{ Parameter Levels } \\
\hline Name & Symbols & Units & $\mathbf{1}$ & $\mathbf{2}$ & $\mathbf{3}$ & $\mathbf{4}$ \\
\hline Spindle Rotational Speed & A & $\mathrm{rpm}$ & 400 & 900 & 1400 & 2000 \\
Feed Rate & $\mathrm{B}$ & $\mathrm{mm} / \mathrm{min}$ & 100 & 200 & 300 & 400 \\
Depth of Cut & $\mathrm{C}$ & $\mathrm{mm}$ & 0.2 & 0.5 & 0.8 & 1.2 \\
\hline
\end{tabular}

Table 2. Experimental combinations.

\begin{tabular}{cccc}
\hline \multirow{2}{*}{ Experiment Number } & \multicolumn{3}{c}{ Parameters } \\
\cline { 2 - 4 } & Spindle Rotational Speed & Feed Rate & Depth of Cut \\
\hline 1 & 400 & 100 & 0.2 \\
2 & 400 & 200 & 0.5 \\
3 & 400 & 300 & 0.8 \\
4 & 400 & 400 & 1.2 \\
5 & 900 & 100 & 0.5 \\
6 & 900 & 200 & 0.2 \\
7 & 900 & 300 & 1.2 \\
8 & 900 & 400 & 0.8 \\
9 & 1400 & 100 & 0.8 \\
10 & 1400 & 200 & 1.2 \\
11 & 1400 & 300 & 0.2 \\
12 & 1400 & 400 & 0.5 \\
13 & 2000 & 100 & 1.2 \\
14 & 2000 & 200 & 0.8 \\
15 & 2000 & 300 & 0.5 \\
16 & 2000 & 400 & 0.2 \\
\hline
\end{tabular}




\subsection{Material and Equipment}

The material under study - that is, unmodified Calotropis Procera fiber-reinforced PLA composite-was prepared into sixteen samples of approximately $41 \mathrm{~mm}$ by $19 \mathrm{~mm}$ by $4 \mathrm{~mm}$ and labeled according to the experiment number. The material has properties listed in Table 3 . The individual samples were weighed using an electronic weighing scale, and the mass was denoted as M1 (in grams) (Table 4). The samples were then milled in a Benchmill 6000 CNC machine (Intelitek, Derry, NH, USA) using a 3 mm-diameter high-speed steel end mill cutter. An infrared camera (FLIR-E5, Teledyne FLIR LLC, Wilsonville, USA) was used during the experiments to capture thermal images of the tool-workpiece interface at a set distance of $250 \mathrm{~mm}$. The atmospheric and the external optics temperatures were assumed to be equivalent to the room temperatures of approximately $22{ }^{\circ} \mathrm{C}$. The relative humidity was taken as $63 \%$. The emissivity of the UCPFRPC was adopted as $0.96[15,16]$. Three thermal images for each experiment were obtained from which the average milling temperatures were obtained. The machining time $(\mathrm{T})$ was also recorded in seconds. The experimental setup is shown in Figure 1.

Table 3. Properties of UCPFRPC.

\begin{tabular}{ccc}
\hline S/N & Property & Value \\
\hline 1 & Density & $1225.8 \mathrm{~kg} / \mathrm{cm}^{3}$ \\
2 & Composition & $20 \% \mathrm{CP}+80 \%$ PLA \\
\hline
\end{tabular}

Table 4. Experimental Results.

\begin{tabular}{|c|c|c|c|c|c|c|c|c|c|c|c|c|}
\hline \multirow{2}{*}{$\begin{array}{l}\text { Experiment } \\
\text { Number }\end{array}$} & \multicolumn{4}{|c|}{ Surface Roughness } & \multicolumn{4}{|c|}{ Material Removal Rate } & \multicolumn{4}{|c|}{ Milling Temperature } \\
\hline & $\begin{array}{c}\mathrm{Ra}_{1} \\
(\mu \mathrm{m})\end{array}$ & $\begin{array}{c}\mathrm{Ra}_{2} \\
(\mu \mathrm{m})\end{array}$ & $\begin{array}{c}\mathrm{Ra}_{3} \\
(\mu \mathrm{m})\end{array}$ & $\begin{array}{c}R a_{\text {Average }} \\
(\mu \mathrm{m})\end{array}$ & $\mathbf{M}_{1}(\mathrm{~g})$ & $\mathbf{M}_{2}(\mathrm{~g})$ & $\mathrm{T}(\mathrm{s})$ & $\begin{array}{l}\text { MRR } \\
\left(\mathrm{m}^{3} / \mathrm{S}\right)\end{array}$ & $\begin{array}{c}\mathrm{T}_{1} \\
\left({ }^{\circ} \mathrm{C}\right)\end{array}$ & $\begin{array}{c}\mathrm{T}_{2} \\
\left({ }^{\circ} \mathrm{C}\right)\end{array}$ & $\begin{array}{c}\mathrm{T}_{3} \\
\left({ }^{\circ} \mathrm{C}\right)\end{array}$ & $\begin{array}{c}\mathrm{T}_{\text {Average }} \\
\left({ }^{\circ} \mathrm{C}\right)\end{array}$ \\
\hline 1 & 0.858 & 0.993 & 0.862 & 0.904 & 3.896 & 3.845 & 68 & 4.251 & 33.7 & 32.6 & 32.1 & 32.8 \\
\hline 2 & 1.107 & 1.267 & 1.074 & 1.149 & 3.909 & 3.752 & 38 & 7.313 & 45.8 & 40.8 & 41.6 & 42.7 \\
\hline 3 & 1.287 & 1.253 & 1.438 & 1.326 & 4.261 & 4.041 & 25 & 6.742 & 48.1 & 45.4 & 46.2 & 46.6 \\
\hline 4 & 1.270 & 1.487 & 1.431 & 1.396 & 3.779 & 3.456 & 20 & 7.919 & 58.8 & 61.2 & 53.4 & 57.8 \\
\hline 5 & 1.119 & 1.060 & 1.097 & 1.092 & 3.973 & 3.933 & 68 & 3.334 & 33.9 & 32.2 & 28.8 & 31.6 \\
\hline 6 & 0.976 & 0.978 & 1.031 & 0.995 & 4.008 & 3.956 & 35 & 2.231 & 39.4 & 37.2 & 36.1 & 37.6 \\
\hline 7 & 1.652 & 1.611 & 1.735 & 1.666 & 3.894 & 3.548 & 25 & 10.603 & 70.0 & 65.2 & 57.5 & 64.2 \\
\hline 8 & 1.232 & 1.185 & 1.201 & 1.206 & 4.027 & 3.798 & 19 & 5.333 & 58.8 & 46.3 & 48.4 & 51.2 \\
\hline 9 & 3.122 & 2.428 & 3.609 & 3.053 & 3.773 & 3.530 & 70 & 20.851 & 75.5 & 71.3 & 63.7 & 70.2 \\
\hline 10 & 2.490 & 2.081 & 1.908 & 2.160 & 3.876 & 3.559 & 37 & 14.377 & 68.9 & 73.8 & 73.0 & 71.9 \\
\hline 11 & 1.020 & 1.121 & 0.944 & 1.028 & 3.955 & 3.932 & 24 & 0.677 & 33.2 & 35.5 & 33.7 & 34.1 \\
\hline 12 & 0.949 & 1.049 & 0.859 & 0.952 & 3.908 & 3.874 & 19 & 0.792 & 36.1 & 35.5 & 31.6 & 34.4 \\
\hline 13 & 1.840 & 2.291 & 2.082 & 2.071 & 3.982 & 3.696 & 71 & 24.891 & 83.6 & 74.6 & 91.6 & 83.3 \\
\hline 14 & 3.119 & 3.090 & 2.722 & 2.977 & 4.043 & 3.812 & 36 & 10.194 & 76.6 & 76.3 & 89.4 & 80.8 \\
\hline 15 & 1.895 & 1.931 & 1.190 & 1.672 & 3.945 & 3.871 & 24 & 2.177 & 45.8 & 50.0 & 55.4 & 50.4 \\
\hline 16 & 1.491 & 1.425 & 1.235 & 1.384 & 3.842 & 3.780 & 19 & 1.444 & 49.8 & 46.3 & 50.4 & 48.8 \\
\hline
\end{tabular}

After milling, the machined surfaces were cleaned, and the workpieces were weighed again to obtain the final mass, $\mathrm{M}_{2}$ (in grams). The workpieces were then investigated for the surface roughness, where three values of the arithmetic mean of surface roughness were obtained for each experiment and the average obtained (Table 4). The MRR was then computed from the change in mass, machining time, and material density, as shown in Equation (1) and recorded in Table 4. 


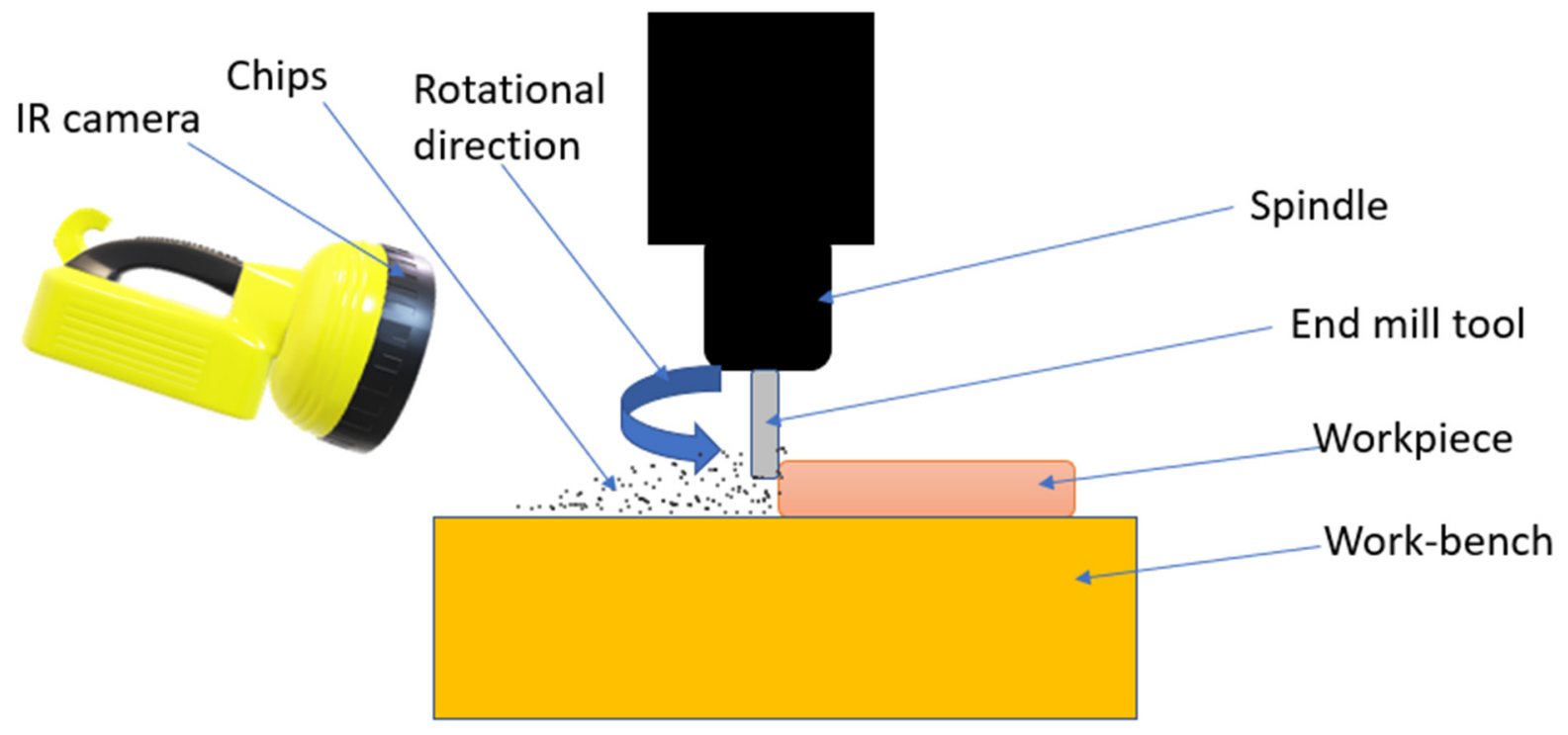

Figure 1. Experimental setup.

$$
\operatorname{MRR}\left(\frac{m^{3}}{S}\right)=\frac{\mathrm{M}_{2}-\mathrm{M}_{1}}{\mathrm{~T} \times \rho}
$$

where $\mathrm{M}_{1}=$ Workpiece initial mass.

$\mathrm{M}_{2}=$ Workpiece final mass.

$\mathrm{T}=$ Machining time.

$\rho=$ Material density.

\section{Results}

The results obtained for the average milling temperatures, surface roughness, and material removal rate were recorded in Table 4 .

The Taguchi methodology was adopted in the optimization process. The primary goal was to obtain the optimal machining parameters for the least surface roughness, the highest material removal rate, and the least possible average milling temperatures. In the Taguchi analysis, the Signal-to-Noise (S/N) ratios were adopted to assess the interaction of parameters and determine the optimal parameters. In the generation of the $\mathrm{S} / \mathrm{N}$ ratios for the surface roughness and the average milling temperatures, the "smaller-is-better" criterion was used to minimize these responses. In contrast, the "larger-is-better" criterion was adopted to maximize the parameters for the material removal rate. As a result, the $S / \mathrm{N}$ ratios were obtained from the Taguchi analysis as shown in response Tables 5-7, for the average surface roughness, material removal rate, and milling temperatures, respectively. A sample IR image of one of the samples is presented in Figure 2.

Table 5. S/N ratios response table for average surface roughness.

\begin{tabular}{cccc}
\hline Parameter Level & Spindle Rotational Speed & Feed Rate & Depth of Cut \\
\hline 1 & -1.4196 & -3.9765 & -0.5356 \\
\hline 2 & -1.6953 & -4.3319 & -1.5021 \\
\hline 3 & -4.0491 & -2.8972 & -5.8120 \\
\hline 4 & -5.7717 & -1.7300 & -5.0860 \\
\hline Delta & 4.3521 & 2.6018 & 5.2764 \\
\hline Rank & 2 & 3 & 1 \\
\hline
\end{tabular}


Table 6. S/N ratios response table for MRR.

\begin{tabular}{cccc}
\hline Parameter Level & Spindle Rotational Speed & Feed Rate & Depth of Cut \\
\hline 1 & 16.100 & 19.333 & 4.836 \\
\hline 2 & 13.119 & 16.893 & 8.118 \\
\hline 3 & 11.031 & 10.113 & 19.416 \\
\hline 4 & 14.509 & 8.420 & 22.389 \\
\hline Delta & 5.070 & 10.913 & 17.553 \\
\hline Rank & 3 & 2 & 1 \\
\hline
\end{tabular}

Table 7. S/N ratios response table for average milling temperature.

\begin{tabular}{cccc}
\hline Parameter Level & Spindle Rotational Speed & Feed Rate & Depth of Cut \\
\hline 1 & -32.88 & -33.91 & -31.56 \\
\hline 2 & -32.96 & -34.85 & -31.85 \\
\hline 3 & -33.86 & -33.56 & -35.66 \\
\hline 4 & -36.09 & -33.48 & -36.73 \\
\hline Delta & 3.21 & 1.37 & 5.17 \\
\hline Rank & 2 & 3 & 1 \\
\hline
\end{tabular}

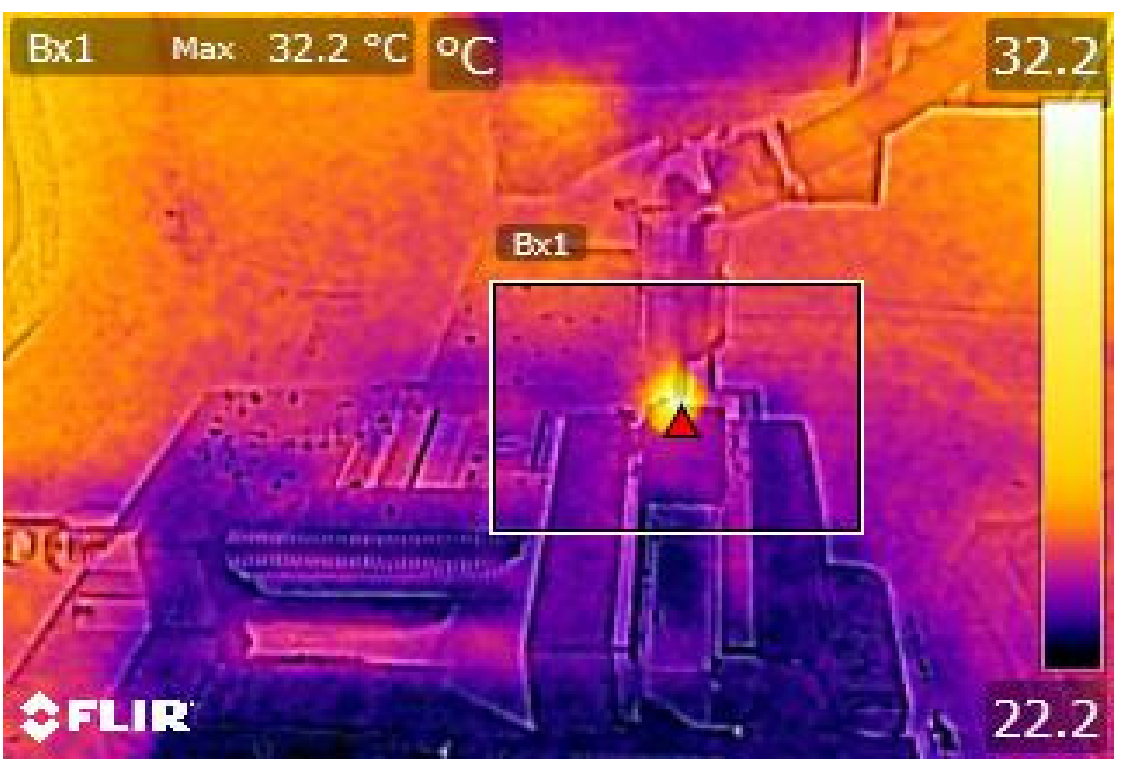

Figure 2. IR image of sample during machining.

The largest $\mathrm{S} / \mathrm{N}$ ratio in Table 5 was used to identify the optimal machining parameters for the least surface roughness. It could be observed that the depth of cut had the largest impact on the surface roughness, followed by the spindle rotational speed, and lastly, the feed rate, as indicated by the delta value. Further, the largest $\mathrm{S} / \mathrm{N}$ ratio for the spindle rotational speed was -1.4196 , corresponding to the first level; that is, $400 \mathrm{rpm}$. The largest $\mathrm{S} / \mathrm{N}$ ratios for the feed rate and depth of cut were -1.73 and -0.5356 , corresponding to levels 4 and 1, i.e., $400 \mathrm{~mm} / \mathrm{min}$ and $0.2 \mathrm{~mm}$, respectively. These $\mathrm{S} / \mathrm{N}$ ratios are also presented in Figure 3, showing a decreasing trend with increasing spindle rotational speed and depth of cut. The $\mathrm{S} / \mathrm{N}$ ratios increased as the feed rate increased. Therefore, the optimal UCPFRPC milling parameters for the least surface roughness are $400 \mathrm{rpm}$ for spindle rotational speed, $400 \mathrm{~mm} / \mathrm{min}$ for feed rate, and $0.2 \mathrm{~mm}$ for the depth of cut. 


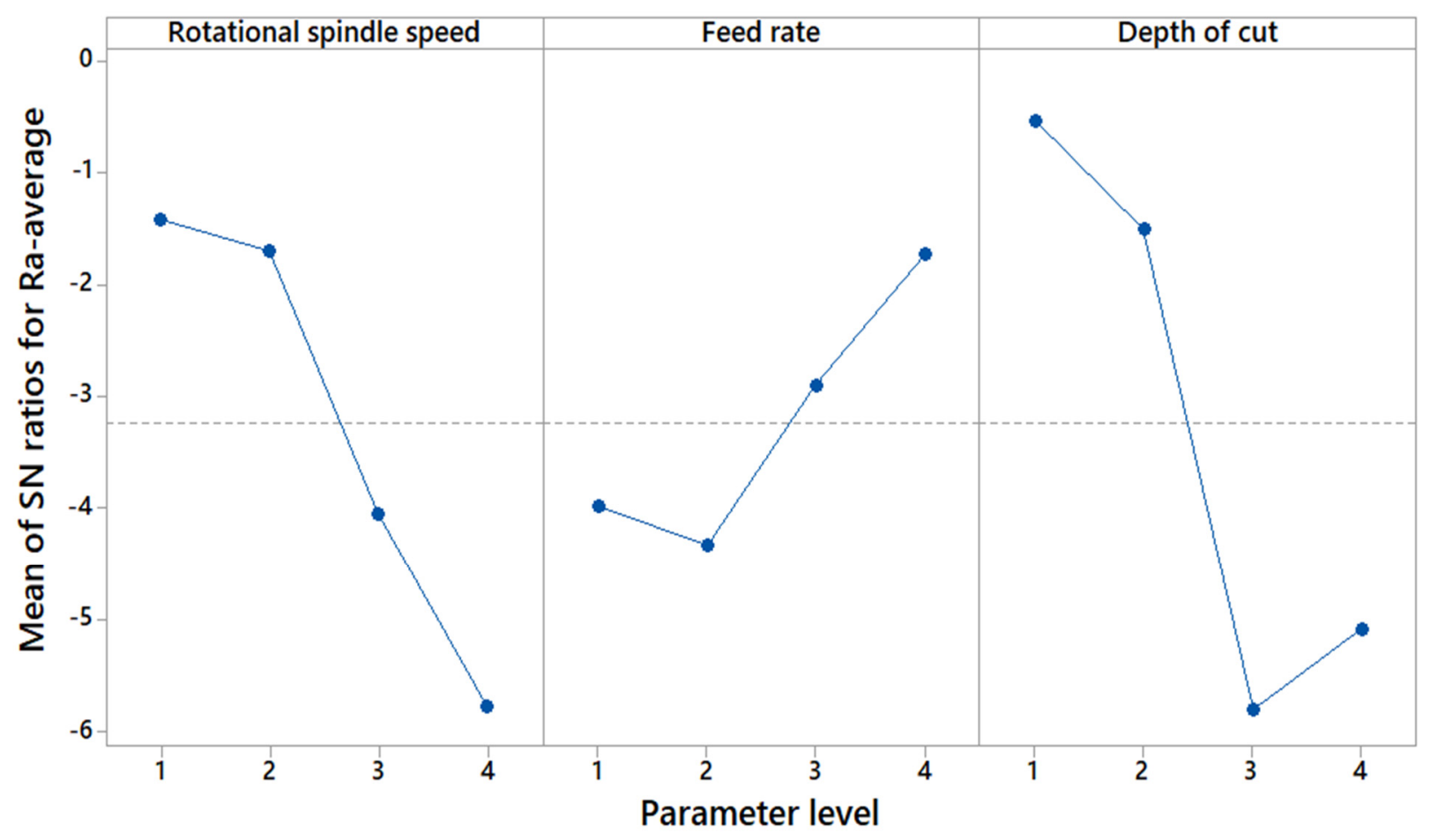

Figure 3. Average surface roughness main effect plots for $\mathrm{S} / \mathrm{N}$ ratios.

The low spindle speed and depth of cut meant a small cutting speed which reduced the rate of chip build-up. This reduced the rate of surface breakage and hence a better surface finish. Further, a lower spindle rotational speed reduced heat generation at the tool-workpiece interface, and therefore a better surface finish [17]. The high feed rate increased the rate of chip removal, which facilitated heat dissipation and, hence, lower surface damage [18]. However, the feed rate results differed from those obtained in the milling of other composites, where the feed rate was identified to vary inversely with the surface roughness $[19,20]$. Being a virgin material, this variation was acceptable.

Similarly, the mean S/N ratios for the MRR are presented in Table 6.

The largest $\mathrm{S} / \mathrm{N}$ ratios for the spindle rotational speed, feed rate, and depth of cut are 16.1, 19.333, and 22.389, respectively. These correspond to level one of spindle speed $(400 \mathrm{rpm})$, level one of feed rate $(100 \mathrm{~mm} / \mathrm{min})$, and level four of the depth of cut $(1.2 \mathrm{~mm})$. These optimal parameters are also depicted in Figure 4. Considering the delta value, it was observed that the depth of cut had the largest effect on the MRR during the milling of unmodified Calotropis Procera fiber-reinforced PLA composite. The feed rate followed this, and finally, the spindle rotational speed. Similar results were obtained in several composite machining studies conducted $[17,21]$. Furthermore, increasing the depth of cut increases the volume swept by the tool and the feed per tooth, increasing the material removal [17]. However, the outputs of the rotational spindle speed and the feed rate were different from other studies that depict that an increase in milling parameters increases the rate of material removal [22].

The analysis was repeated for the average milling temperature and the mean $\mathrm{S} / \mathrm{N}$ ratios recorded in Table 7.

The most impactful parameter towards the average milling temperature was the depth of cut, followed by the spindle rotational speed, and finally, the feed rate. The largest S/N ratios for the spindle rotational speed, feed rate, and depth of cut were $-32.88,-33.48$, and -31.56 , respectively. These $\mathrm{S} / \mathrm{N}$ ratios are also presented in Figure 5. The optimal milling parameters for the least milling temperature corresponding to the largest $\mathrm{S} / \mathrm{N}$ ratios were spindle speed of $400 \mathrm{rpm}$, feed rate of $400 \mathrm{~mm} / \mathrm{min}$, and depth of cut of $0.2 \mathrm{~mm}$. Figure 5 depicts that increasing the spindle rotational speed and depth of cut leads to a decrease in 
the average milling temperature. However, the average milling temperatures increase as the feed rate increases.

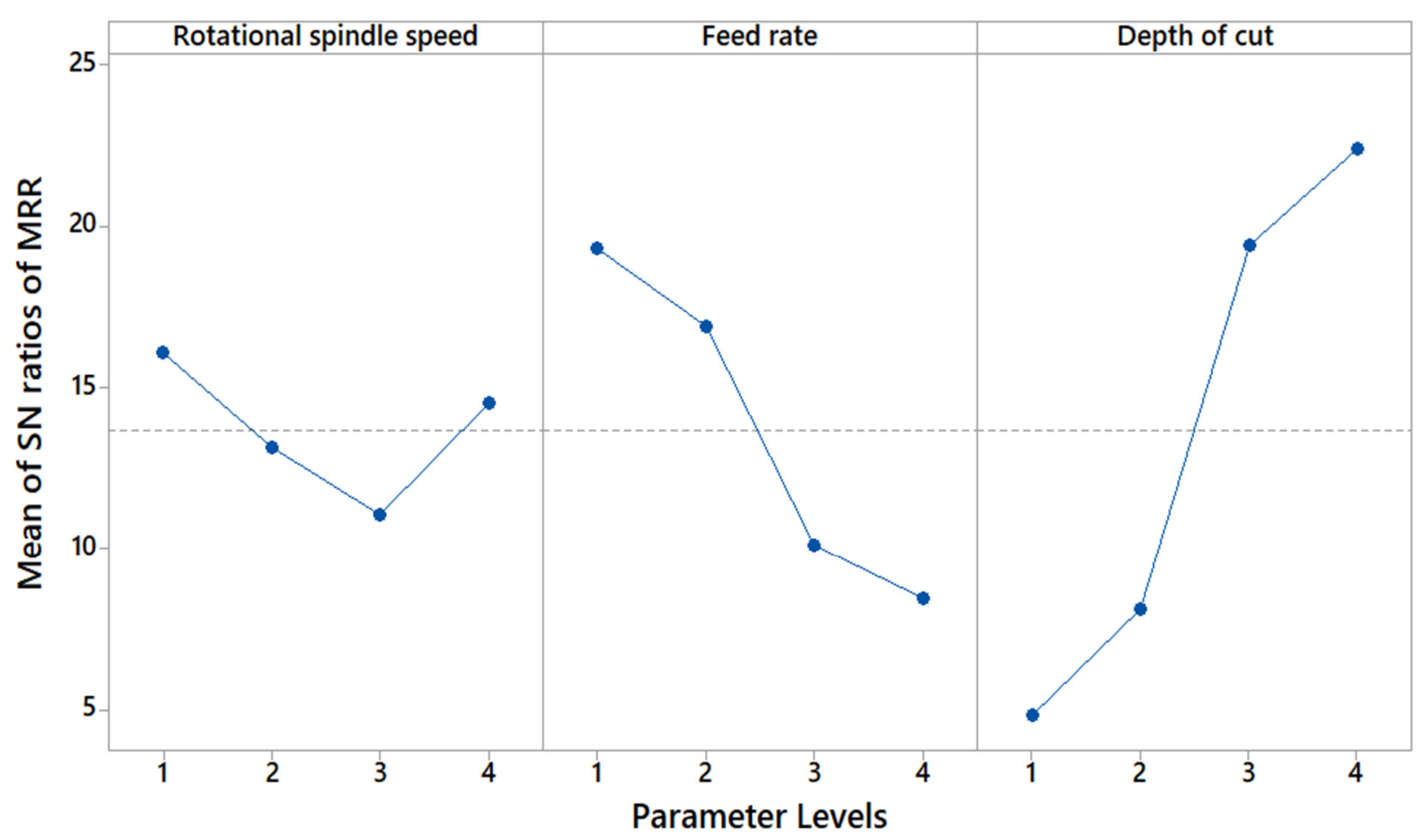

Figure 4. MRR main effect plots for $\mathrm{S} / \mathrm{N}$ ratios.

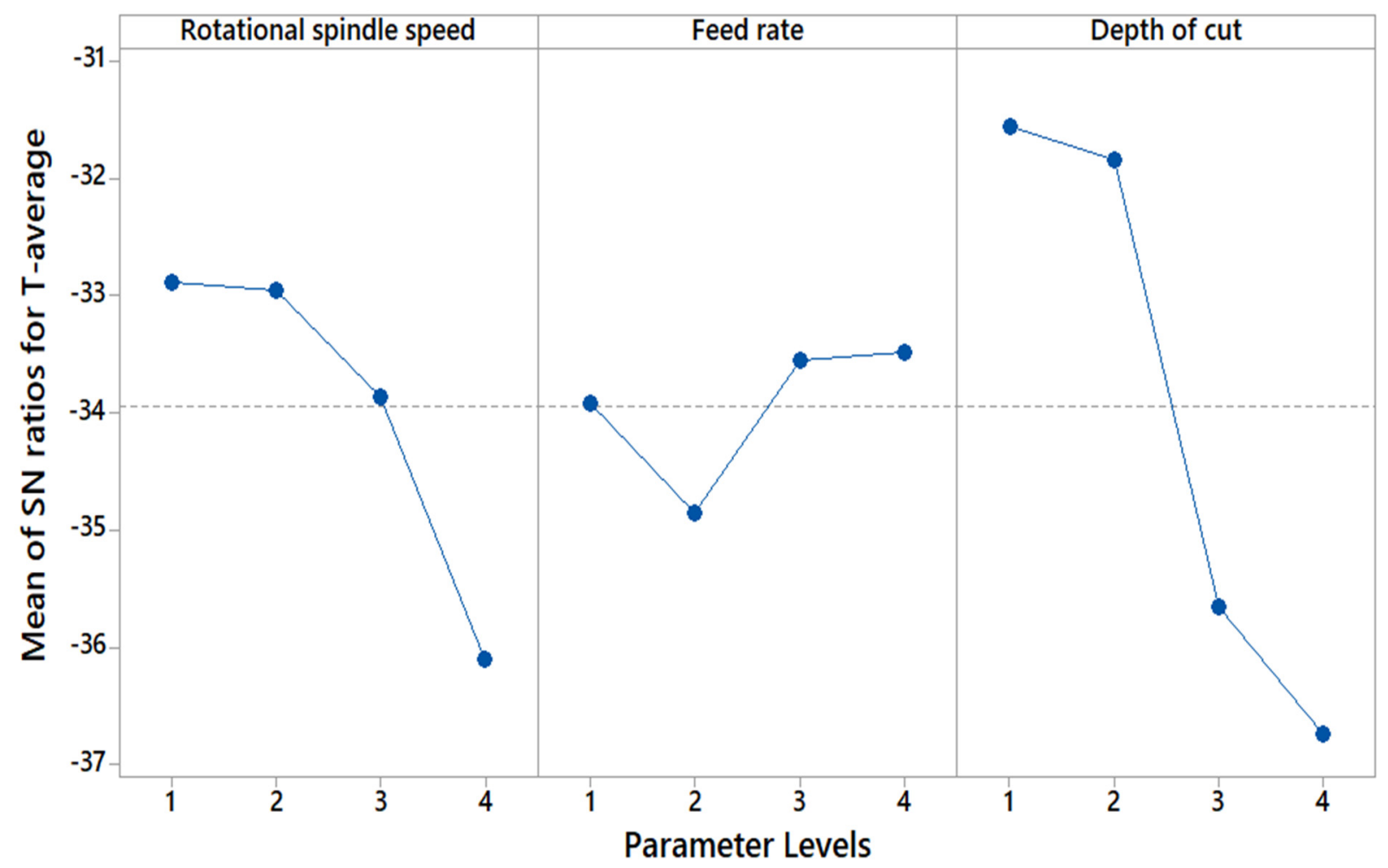

Figure 5. Average milling temperature main effect plots for $\mathrm{S} / \mathrm{N}$ ratios.

A higher feed rate coupled with a low cutting depth reduced the build-up of chips as more chips were evacuated as the tool advanced the workpiece. This reduced the friction force and increased heat dissipation, hence lower milling temperatures [18]. However, an 
increase in the spindle speed led to a rise in the heat energy converted from the severe plastic deformation of the UCPFRPC. A high speed also translated to high tool-workpiece friction and hence high milling temperature [12].

The analysis of variance (ANOVA) was then carried out with a significance value of 0.05 to evaluate the significance of each parameter towards the surface roughness, MRR, and the average milling temperature. For the surface roughness, the ANOVA outputs are recorded in Table 8.

Table 8. ANOVA for the surface roughness.

\begin{tabular}{ccccccc}
\hline Source & DF & SS & MS & \% Contribution & F-Value & $p$-Value \\
\hline Spindle rotational speed & 3 & 2.042 & 0.681 & 29.55 & 4.66 & 0.05 \\
\hline Feed rate & 3 & 0.963 & 0.321 & 13.94 & 2.20 & 0.19 \\
\hline Depth of cut & 3 & 3.028 & 1.009 & 43.82 & 6.91 & 0.02 \\
\hline Error & 6 & 0.877 & 0.146 & & & \\
\hline Total & 15 & 6.910 & & & & \\
\hline
\end{tabular}

The ANOVA showed that the spindle rotational speed $(p$-value $=0.05)$ and depth of cut $(p$-value $=0.02)$ were significant towards the surface roughness. On the other hand, the feed rate was identified to be insignificant towards the surface roughness $(p$-value $=0.19$ ). The depth of cut contributed the highest towards the surface roughness $(43.82 \%)$, followed by the spindle rotational speed $(29.55 \%)$, and lastly, the feed rate $(13.94 \%)$.

Similarly, an ANOVA for the MRR was conducted, as shown in Table 9. For a significance value of 0.05 , the $p$-values were $0.35,0.04$, and 0.01 for the spindle rotational speed, feed rate, and depth of cut, respectively. This showed that the feed rate and depth of cut were highly significant towards the MRR, while the rotational spindle speed was not. The depth of cut contributed the highest to the MRR (54.73\%). The second one was the feed rate $(28.39 \%)$ and the spindle rotational speed $(6.72 \%)$.

Table 9. ANOVA for the MRR.

\begin{tabular}{ccccccc}
\hline Source & DF & SS & MS & \% Contribution & F-Value & $p$-Value \\
\hline Spindle rotational speed & 3 & 51.17 & 17.06 & 6.72 & 1.32 & 0.35 \\
\hline Feed rate & 3 & 216.32 & 72.11 & 28.39 & 5.59 & 0.04 \\
\hline Depth of cut & 3 & 417.06 & 139.02 & 54.73 & 10.77 & 0.01 \\
\hline Error & 6 & 77.43 & 12.90 & & & \\
\hline Total & 15 & 761.98 & & & & \\
\hline
\end{tabular}

Lastly, the ANOVA for the average milling temperature (Table 10) showed that the rotational spindle speed $(p$-value $=0.00)$ and the depth of cut $(p$-value $=0.00)$ are significant determinants. The feed rate was insignificant towards the average milling temperature ( $p$-value $=0.06)$. The depth of cut was the largest contributing parameter towards the average milling temperature with $66.18 \%$. The spindle rotational speed was the second contributing parameter $(24.57 \%)$, and lastly, the feed rate $(6.29 \%)$. 
Table 10. ANOVA for the average milling temperature.

\begin{tabular}{ccccccc}
\hline Source & DF & SS & MS & \% Contribution & F-Value & $p$-Value \\
\hline Spindle rotational speed & 3 & 1097.9 & 365.98 & 24.57 & 16.60 & 0.00 \\
\hline Feed rate & 3 & 280.9 & 93.64 & 6.29 & 4.25 & 0.06 \\
\hline Depth of cut & 3 & 2956.6 & 985.53 & 66.18 & 44.71 & 0.00 \\
\hline Error & 6 & 132.3 & 22.04 & & & \\
\hline Total & 15 & 4467.7 & & & & \\
\hline
\end{tabular}

\section{Conclusions}

From the milling of unmodified Calotropis Procera fiber-reinforced PLA composite conducted in this study, the following conclusions were drawn:

1. The optimal milling parameters for the least surface roughness are $400 \mathrm{rpm}, 400 \mathrm{~mm} / \mathrm{min}$, and $0.2 \mathrm{~mm}$ for the rotational spindle speed, feed rate, and depth of cut. The depth of cut is the highest contributing parameter $(43.82 \%)$, while the feed rate contributes the least towards the surface roughness (13.94\%).

2. The optimal milling parameters for the highest MRR are a spindle speed of $400 \mathrm{rpm}$, a feed rate of $100 \mathrm{~mm} / \mathrm{min}$, and a depth of cut of $1.2 \mathrm{~mm}$. The depth of cut contributes the largest towards the MRR $(54.73 \%)$, while the spindle rotational speed contributes the least $(6.72 \%)$.

3. The optimal milling parameters for the least average milling temperature are a spindle speed of $400 \mathrm{rpm}$, a feed rate of $400 \mathrm{~mm} / \mathrm{min}$, and a depth of cut of $0.2 \mathrm{~mm}$. The depth of cut contributes the largest $(66.18 \%)$, while the feed rate contributes the least towards the average milling temperature $(6.29 \%)$.

Author Contributions: Conceptualization, H.K.L., F.M.M. and J.M.W.; Funding acquisition, E.T.A. Investigation, H.K.L.; Methodology, H.K.L.; Supervision, J.N.K., E.T.A. and T.-C.J.; Writing-original draft, H.K.L. and F.M.M.; Writing-review \& editing, F.M.M., J.M.W. and T.-C.J. All authors have read and agreed to the published version of the manuscript.

Funding: This research received no external funding.

Institutional Review Board Statement: Not applicable.

Informed Consent Statement: Not applicable.

Data Availability Statement: This study presents all the data adopted in the analysis.

Acknowledgments: This research Project was supported by Deutscher Akademischer Austausch Dients (DAAD) through BridGiT (Bridging the Gap through intercultural Engineering Transposition) collaboration between Dedan Kimathi University of Technology and Technical University of Applied Sciences, Wildau- Germany.

Conflicts of Interest: The authors declare no known conflict of interest on the material, method, and results used in this study.

\section{References}

1. Al-Oqla, F.M.; Sapuan, S.M. Natural fiber reinforced polymer composites in industrial applications: Feasibility of date palm fibers for sustainable automotive industry. J. Clean. Prod. 2014, 66, 347-354. [CrossRef]

2. Yousif, B.F.; Shalwan, A.; Chin, C.W.; Ming, K.C. Flexural properties of treated and untreated kenaf/epoxy composites. Mater. Des. 2012, 40, 378-385. [CrossRef]

3. Vaneewari, N.; Saranya, D.V. Effect of silane coupling agent on the mechanical steel of sugarcane baggase and polypropylene composites. Mater. Today Proc. 2021. [CrossRef]

4. Mazzanti, V.; de Luna, M.S.; Pariante, R.; Mollica, F.; Filippone, G. Natural fiber-induced degradation in PLA-hemp biocomposites in the molten state. Compos. Part A Appl. Sci. Manuf. 2020, 137, 105990. [CrossRef]

5. Motru, S.; Adithyakrishna, V.H.; Bharath, J.; Guruprasad, R. Development and Evaluation of Mechanical Properties of Biodegradable PLA/Flax Fiber Green Composite Laminates. Mater. Today Proc. 2020, 24, 641-649. [CrossRef] 
6. Rajeshkumar, G.; Seshadri, S.; Devnani, G.; Sanjay, M.; Siengchin, S.; Maran, J.; Al-Dhabi, N.; Karuppiah, P.; Mariadhas, V.; Sivarajasekar, N.; et al. Environment friendly, renewable and sustainable poly lactic acid (PLA) based natural fiber reinforced composites-A comprehensive review. J. Clean. Prod. 2021, 310, 127483. [CrossRef]

7. Codolini, A.; Li, Q.M.; Wilkinson, A. Influence of machining process on the mechanical behaviour of injection-moulded specimens of talc-filled Polypropylene. Polym. Test. 2017, 62, 342-347. [CrossRef]

8. Chegdani, F.; el Mansori, M. Mechanics of material removal when cutting natural fiber reinforced thermoplastic composites. Polym. Test. 2018, 67, 275-283. [CrossRef]

9. Wang, D.; Onawumi, P.Y.; Ismail, S.O.; Dhakal, H.N.; Popov, I.; Silberschmidt, V.V.; Roy, A. Machinability of natural-fibrereinforced polymer composites: Conventional vs. ultrasonically-assisted machining. Compos. Part A Appl. Sci. Manuf. 2019, 119, 188-195. [CrossRef]

10. Mutalib, M.Z.A.; Jamal, M.J.; Ahmad, S.A.S. Effect of Machining Parameters on Delamination during Milled Banana FiberReinforced Polyester Composites. J. Eng. Sci. Res. 2017, 1, 8-10. Available online: http://ir.unikl.edu.my/jspui/handle/12345678 9/4572 (accessed on 20 August 2021).

11. Wan, M.; Li, S.E.; Yuan, H.; Zhang, W.H. Cutting force modelling in machining of fiber-reinforced polymer matrix composites (PMCs): A review. Compos. Part A Appl. Sci. Manuf. 2019, 117, 34-55. [CrossRef]

12. Wang, H.; Sun, J.; Zhang, D.; Guo, K.; Li, J. The effect of cutting temperature in milling of carbon fiber reinforced polymer composites. Compos. Part A Appl. Sci. Manuf. 2016, 91, 380-387. [CrossRef]

13. Kiran; Nagamadhu, M.; Jaiprakash, M.; Karthikeyan, K.; Shariff, M. Study the impact of drilling process parameters on natural fiber reinforced chaired epoxy composites. Mater. Today Proc. 2019, 24, 2204-2218. [CrossRef]

14. Gohil, P.; Patel, K.; Chaudhary, V. Natural fiber-reinforced polymer composites: A comprehensive study on machining characteristics of hemp fiber-reinforced composites. In Biomass, Biopolymer-Based Materials, and Bioenergy, 1st ed.; Woodhead Publishing Series in Composites Science and Engineering: Amsterdam, The Netherlands, 2019; pp. 25-50.

15. Tychanicz-Kwiecien, M.; Smusz, R.; Gil, P. Performance of Thermal Insulation Fabricated By Rapid Prototyping Technology. Therm. Sci. 2019, 23, S1079-S1090. [CrossRef]

16. Antar, Z.; Noel, H.; Feller, J.F.; Glouannec, P.; Elleuch, K. Thermophysical and Radiative Properties of Conductive Biopolymer Composite. Mater. Sci. Forum 2012, 714, 115-122. [CrossRef]

17. Deepak, D.; Rajendra, B. The effect of Process Parameters on Material Removal Rate in Drilling of Al 6061-SiC composite. MATEC Web Conf. 2018, 144, 1-7. [CrossRef]

18. Ismail, S.O.; Dhakal, H.N.; Popov, I.; Beaugrand, J. Comprehensive study on machinability of sustainable and conventional fibre reinforced polymer composites. Eng. Sci. Technol. Int. J. 2016, 19, 2043-2052. [CrossRef]

19. Sharma, A.; Dwivedi, V.K. Effect of milling parameters on surface roughness: An experimental investigation. Mater. Today Proc. 2019, 25, 868-871. [CrossRef]

20. Çelik, Y.H.; Kilickap, E.; Kilickap, A.İ. An experimental study on milling of natural fiber (jute)-reinforced polymer composites. J. Compos. Mater. 2019, 53, 3127-3137. [CrossRef]

21. Shagwira, H.; Mbuya, T.O.; Mwema, F.M.; Herzog, M.; Akinlabi, E.T. Taguchi Optimization of Surface Roughness and Material Removal Rate in CNC Milling of Polypropylene + 5wt.\% Quarry Dust Composites. IOP Conf. Ser. Mater. Sci. Eng. 2021, 1107, 012040. [CrossRef]

22. Rajasekaran, T.; Vinayagam, B.K.; Palanikumar, K.; Prakash, S. Influence of machining parameters on surface roughness and material removal rate in machining carbon fiber reinforced polymer material. Proc. Int. Conf. Front. Automob. Mech. Eng. 2010, 75-80. [CrossRef] 